\title{
INHIBITION OF RENAL ORNITHINE DECARBOXYLASE BY AMINOGLYCOSIDE ANTIBIOTICS IN VITRO
}

\author{
Charles M. Henley III, Laila G. Mahran and Jochen Schacht* \\ Kresge Hearing Research Institute, University of Michigan, Ann Arbor, MI 48109, U.S.A.
}

(Received 13 March 1987; accepted 5 October 1987)

\begin{abstract}
The inhibition of renal ornithine decarboxylase (ODC) by aminoglycoside antibiotics was characterized in the postmitochondrial fraction of a kidney homogenate from adult pigmented guinea pigs. Enzymatic activity was defined as the rate of decarboxylation of $\left[{ }^{14} \mathrm{C}\right]$ ornithine sensitive to a specific ODC inhibitor, $\alpha$-difuoromethylornithine (DFMO). The $K_{m}$ for ornithine was $61 \pm 32 \mu \mathrm{M}$. There were two forms of the enzyme with respect to their affinity for pyridoxal phosphate (PLP): (I) $K_{m}=$ $2.1 \pm 1.8 \mu \mathrm{M}$; (II) $K_{m}=36.2 \pm 12.7 \mu \mathrm{M}$. Putrescine, a known ODC inhibitor, acted competitively on the renal enzyme with $K_{i}=1.7 \pm 1.4 \mathrm{mM}$. Aminoglycoside antibiotics inhibited ODC by an uncompetitive mechanism with inhibitor constants of comparable magnitude: neomycin, $K_{i}=1.3 \pm 0.1 \mathrm{mM}$; gentamicin, $K_{i}=1.6 \pm 0.1 \mathrm{mM}$; kanamycin, $K_{i}=1.9 \pm 0.2 \mathrm{mM}$; and netilmicin, $K_{i}=1.7 \pm 0.2 \mathrm{mM}$. Neomycin inhibited both forms of the enzyme (low and high affinity for PLP) uncompetitively with similar inhibitor constants $(1.5 \pm 0.3$ and $1.8 \pm 0.4 \mathrm{mM}$ respectively), suggesting a single mechanism of action. Inhibition of $O D C$ suggests that aminoglycoside-polyamine interactions may be an important component of the sequence of biochemical events associated with aminoglycoside toxicity.
\end{abstract}

Aminoglycoside antibiotics such as neomycin and gentamicin and the polyamines putrescine, spermidine and spermine not only share chemical features as polycations but also a number of pharmacological actions. Discrete interactions between aminoglycosides and polyamines which may relate to the mechanism of aminoglycoside toxicity have been described in bacteria as well as mammalian tissues. For example, spermidine and the aminoglycosides competitively inhibit binding of dihydrostreptomycin (DHS) to cell wall teichoic acids isolated from various gram-positive eubacteria [1]. Spermine and spermidine share renal binding sites with aminoglycosides [2], and the aminoglycosides compete for active polyamine transport in both the kidney [3] and the inner ear [4].

Biochemical studies to elucidate nephrotoxic and ototoxic actions of aminoglycosides have provided evidence for a multi-step model of toxicity which proposes an initial interaction between the drugs and the plasma membrane, followed by an energydependent uptake process competitive with polyamines, and finally intracellular binding [4-6]. To characterize further the potential role of aminoglycoside interactions with polyamines in this injury cascade, we studied the effects of aminoglycosides on the activity of renal ornithine decarboxylase.

Ornithine decarboxylase (ODC) is a key enzyme in the polyamine biosynthetic pathway and subject to feedback-inhibition by its reaction product putrescine, as well as by the other polyamines spermidine and spermine [7]. In view of the known interactions between the polyamines and aminoglycosides, it is plausible that the aminoglycosides may affect this enzyme and, thus, cellular mechanisms regulated by polyamines.

\footnotetext{
* To whom correspondence should be addressed.
}

\section{METHODS}

Kidneys from pigmented guinea pigs $(200-250 \mathrm{~g}$, Murphy Breeding Laboratories, Plainsfield, IN) were homogenized in $50 \mathrm{mM}$ sodium $N$-2-hydroxyethyl-1-piperazine- $N^{\prime}$-2-ethane sulfonic acid (HEPES), $2 \mathrm{mM}$ dithioerythritol (DTE) and $50 \mu \mathrm{M}$ pyridoxal phosphate (PLP), $\mathrm{pH} 7,2$, using a Polytron (Brinkmann, Switzerland) for $10 \mathrm{sec}$. No PLP was added to the homogenization in experiments where the final PLP concentrations were varied. The homogenate $(20 \%$, w/v) was centrifuged at $13,000 \mathrm{~g}$ for $20 \mathrm{~min}$ at $4^{\circ}$, and the supernatant fraction was frozen until assayed for ODC activity by a modification of the method of Russell and Snyder [8]. Aliquots of the supernatant fraction were incubated in test tubes with separate reservoirs for the incubation medium and $\mathrm{H}_{2} \mathrm{SO}_{4}$ and fitted with stoppers holding filter paper disks saturated with $15 \mu \mathrm{l}$ of $40 \% \mathrm{KOH}$. Incubation was for $60 \mathrm{~min}$ at $37^{\circ}$ in a total reaction volume of $100 \mu$ l containing $50 \mathrm{mM}$ HEPES, $2 \mathrm{mM}$ DTE, $0.1 \mathrm{mM}$ EDTA, and $20 \mu \mathrm{g}$ bovine serum albumin (BSA), pH 7.2. Ornithine concentration was $100 \mu \mathrm{M}$ (L- $\left[1-{ }^{14} \mathrm{C}\right]$ ornithine, $52.4 \mathrm{mCi} / \mathrm{mmol}$; New England Nuclear, Boston, MA) and PLP, $50 \mu \mathrm{M}$, except when the $K_{m}$ for these substances or the $K_{i}$ values for the aminoglycosides were determined. In those experiments, ornithine was varied from 25 to $100 \mu \mathrm{M}$, and PLP from 0.5 to $100 \mu \mathrm{M}$. Reactions were terminated by combining $200 \mu \mathrm{l}$ of $4 \mathrm{~N} \mathrm{H}_{2} \mathrm{SO}_{4}$ with the incubation medium and post-incubating for $30 \mathrm{~min}$ to allow for complete liberation of ${ }^{14} \mathrm{CO}_{2}$ and absorption onto the $\mathrm{KOH}$-saturated filter. Radioactivity on the filter disks was quantitated by liquid scintillation counting. Control incubations to account for nonspecific or nonenzymatic decarboxylation were performed in each set of experiments by adding $500 \mu \mathrm{M}$ $\alpha$-difluoromethylornithine (DFMO), a specific, irre- 

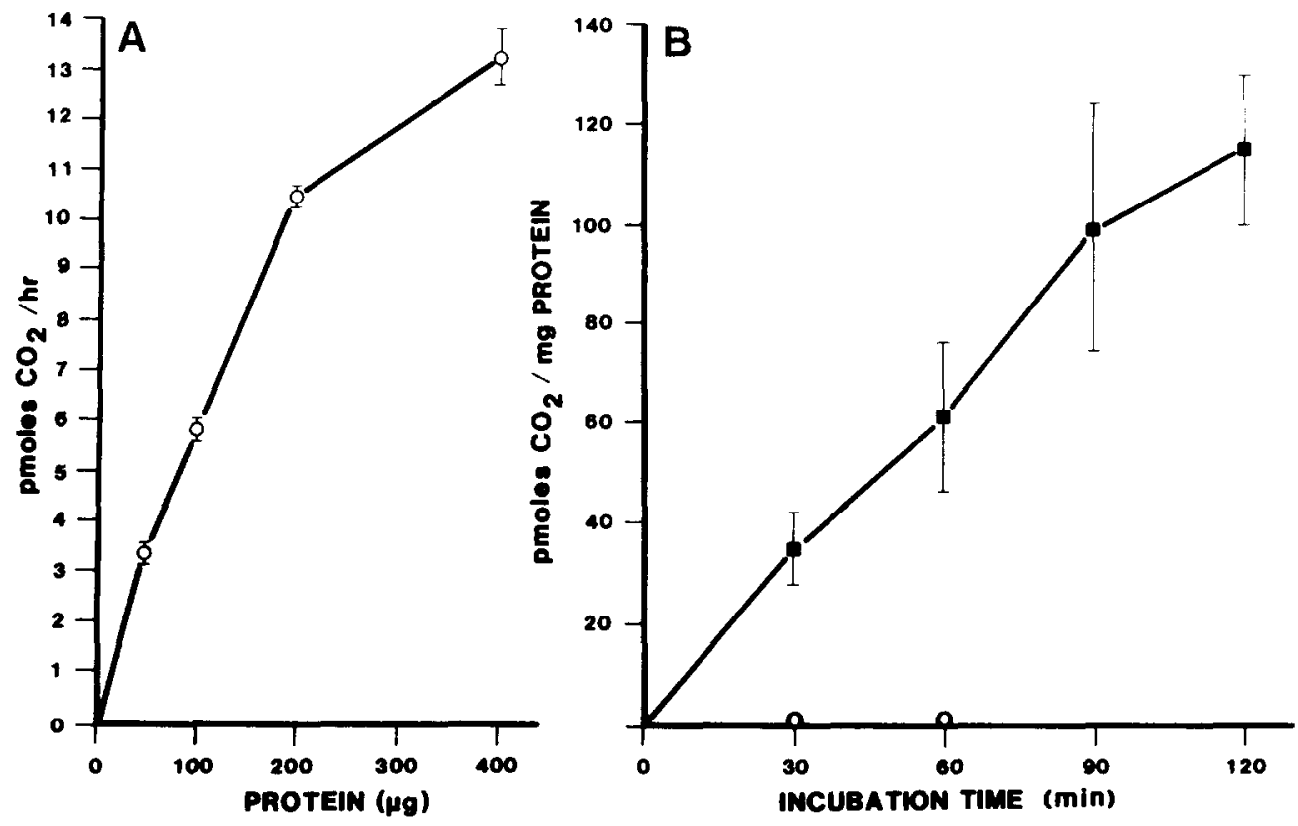

Fig. 1. (A) Effects of protein concentration on the rate of $\mathrm{CO}_{2}$ formation. Experiments were carried out as described in Methods, and the protein concentration in the assay was varied as indicated. Individual points represent means $\pm \mathrm{SD}$ of three incubations each. (B) $\mathrm{CO}_{2}$ formation as a function of the time of incubation. Experiments were carried out as described in Methods with incubation times varied as indicated. Points represent averages of two incubations each. Open circles denote experiments in the presence of DFMO $(500 \mu \mathrm{M})$.

versible inhibitor of ODC, or by substituting BSA $(20 \mu \mathrm{g})$ for the enzyme fraction. Protein was determined with the Bio-Rad assay (Bio-Rad Laboratories, Richmond, CA) using BSA as a standard.

The inhibition by neomycin (Fig. 2, insert) and all other compounds was examined by linear regression analysis of Lineweaver-Burk plots using the Enzpack analytical software (Elsevier Biosoft, Amsterdam). Inhibitor constants were calculated according to Bergmeyer [9] from assays with various inhibitor concentrations.

DFMO was a gift from the Merrell Dow Research Institute (Cincinnati, $\mathrm{OH}$ ). All other chemicals were purchased from the Sigma Chemical Co. (St. Louis, MO).

\section{RESULTS}

Initial experiments demonstrated that the formation of $\mathrm{CO}_{2}$ from $\left[{ }^{14} \mathrm{C}\right]$ ornithine by the renal postmitochondrial fraction was essentially linear with protein concentrations up to $200 \mu \mathrm{g}$ in the assay (Fig. 1A) and incubation times up to $2 \mathrm{hr}$, the longest time tested (Fig. 1B). Enzymatic activity was abolished when 100-500 $\mu \mathrm{M}$ DFMO was added. An incubation time of $60 \mathrm{~min}$ and protein concentrations below $200 \mu \mathrm{g}$ were selected for all subsequent studies.

Since previously reported data on renal ODC come from studies on the rat, mouse or hamster, kinetic parameters were determined for the enzyme preparation from the guinea pig. The analysis of the PLP dependence of the reaction indicated two $K_{m}$ values for PLP: (I) $2.1 \pm 1.8 \mu \mathrm{M}$ and (II) $36.2 \pm 12.7 \mu \mathrm{M}$ with corresponding $V_{\max }$ values of
$22.8 \pm 7.8$ (I) and $109.7 \pm 38.1 \mathrm{pmol} \mathrm{CO}_{2} \cdot \mathrm{hr}^{-1}$. $\mathrm{mg}^{-1}$ (II). In contrast, a single $K_{m}$ of $61 \pm 32 \mu \mathrm{M}$ was evident for ornithine. For the standard assay conditions, $V_{\max }$ ranged from 110 to $142 \mathrm{pmol}$ $\mathrm{CO}_{2} \cdot \mathrm{hr}^{-1} \cdot(\mathrm{mg} \text { protein })^{-1}$ for different preparations of the $13,000 \mathrm{~g}$ supernatant fraction.

The addition of ncomycin to the assay induced a dose-dependent decrease of ODC activity with a half-maximal inhibition in the millimolar range (Fig. 2). Neomycin had no effect on the blank values, i.e. the decarboxylation in the presence of DFMO or with BSA only. The aminoglycoside antibiotics neomycin, kanamycin, gentamicin, and netilmicin all inhibited ODC in an uncompetitive manner (Fig.

Table 1. Inhibition of ornithine decarboxylase

\begin{tabular}{llll}
\hline \multicolumn{1}{c}{ Agent } & $K_{i}(\mathrm{mM})$ & $(\mathrm{N})$ & Type of inhibition \\
\hline Neomycin & $1.3 \pm 0.1$ & $(4)$ & Uncompetitive \\
Gentamicin & $1.6 \pm 0.1$ & $(3)$ & Uncompetitive \\
Netilmicin & $1.7 \pm 0.2$ & $(5)$ & Uncompetitive \\
Kanamycin & $1.9 \pm 0.2$ & $(4)$ & Uncompetitive \\
Putrescine & $1.7 \pm 1.4$ & $(3)$ & Competitive \\
\hline
\end{tabular}

Values represent means $\pm \mathrm{SD}$ of $(\mathrm{N})$ independent experiments. In each experiment, duplicate or triplicate incubations were carried out at each of four different ornithine concentrations $(25-100 \mu \mathrm{M})$. Intercepts were determined by linear regression analysis of LineweaverBurk plots. Correlation coefficients for the individual analyses were: ornithine in the absence of inhibitors, $>0.99$; putrescine and gentamicin, $>0.94$; neomycin, 0.85 to 0.93 ; kanamycin, 0.81 to 0.98 ; and netilmicin, 0.78 to 0.99 . 


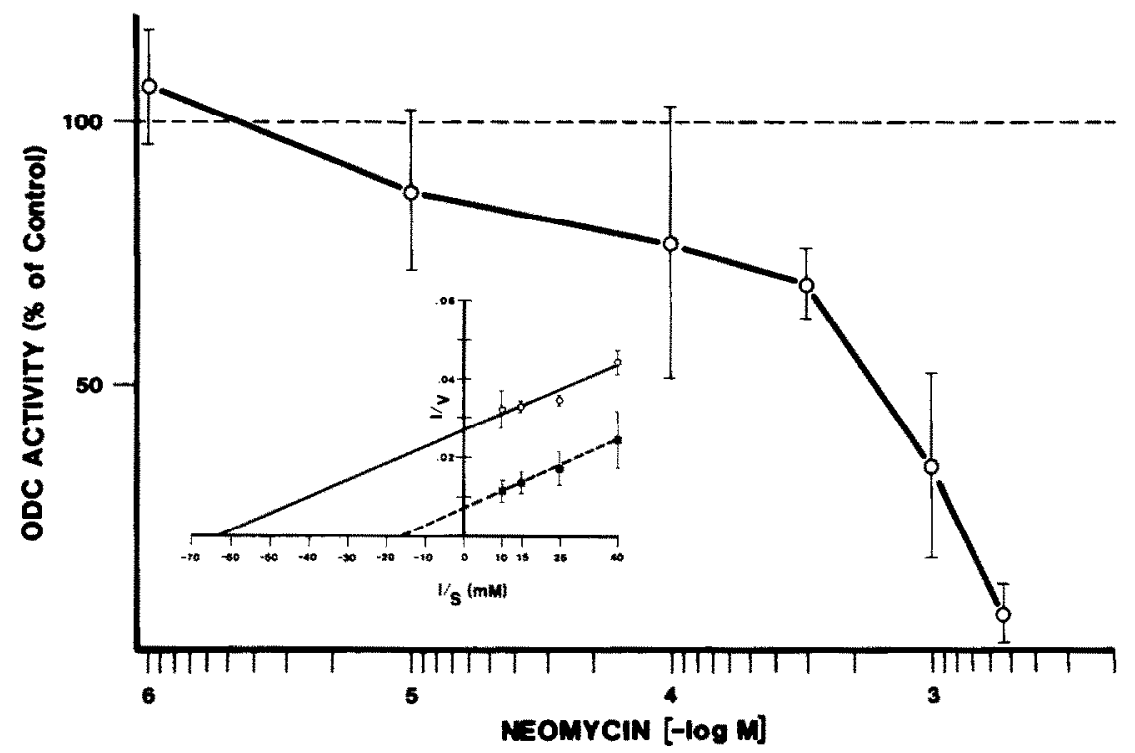

Fig. 2. Inhibition of ornithine decarboxylase activity by neomycin. Experiments were carried out as described in Methods with neomycin added as indicated. Values are expressed as percent of control ODC activity (in the absence of drug) and represent means \pm SD of four to six incubations each. Control $\mathrm{ODC}$ values were $61.8 \pm 14.6 \mathrm{pmol} \mathrm{CO}_{2} \cdot \mathrm{hr}^{-1} \cdot(\mathrm{mg} \text { protein })^{-1}, \mathrm{~N}=21$. Inhibition by $0.5 \mathrm{mM}$ neomycin and above was significant $(P<0.01$, Student's unpaired $t$-test). Insert: Lineweaver-Burk analysis of ODC inhibition by neomycin. Experiments were conducted as described in Methods with various concentrations of ornithine $(25-100 \mu \mathrm{M})$ in the absence $(\nabla)$ and presence $(O)$ of $1 \mathrm{mM}$ neomycin. $V=$ $\mathrm{pmol} \mathrm{CO}_{2} \cdot \mathrm{hr}^{-1} \cdot(\mathrm{mg} \text { protein })^{-1} ; S=$ [ornithine, $\left.\mathrm{mM}\right]$.

2, insert; Table 1) with similar inhibitor constants ranging from $K_{i}=1.3 \pm 0.1 \mathrm{mM}$ (neomycin) to $K_{i}=$ $1.9 \pm 0.2 \mathrm{mM}$ (kanamycin). The two forms of the enzyme with respect to their apparent $K_{m}$ for PLP were both inhibited uncompetitively by neomycin with $K_{i}$ values that did not differ significantly from the $K_{i}$ determined above against various ornithine concentrations: (I) $K_{i}=1.5 \pm 0.3$; (II) $K_{i}=1.8 \pm$ $0.4 \mathrm{mM}$. Putrescine inhibited ODC competitively with $K_{i}=1.7 \pm 1.4 \mathrm{mM}$.

\section{DISCUSSION}

The characteristics of guinea pig renal ODC from the soluble, postmitochondrial supernatant fraction agree well with those from other species: the $K_{m}$ for ornithine $(61 \mu \mathrm{M})$ is within the range of other reported $K_{m}$ values $(60-200 \mu \mathrm{M})$ and the enzyme is inhibited by 0.1 to $0.5 \mathrm{mM}$ DFMO $[7,10]$. Competitive inhibition by putrescine is also in agreement with the effects of putrescine on ODC in other tissues [7]. The presence of two $K_{m}$ values for PLP suggests that the renal enzyme exists in two forms which are distinguished by their affinity to PLP but not ornithine. Two forms of ODC with respect to their $K_{m}$ for PLP have been reported for Physarum polycephalum [11], Swiss 3T3 mouse fibroblasts [12] and Dictyostelium discoideum [13].

The salient point of this study is the finding that aminoglycoside antibiotics inhibited renal ODC. Nephrotoxicity and ototoxicity of these drugs have been recognized for over 40 years; however, only recently has a plausible hypothesis been proposed to explain the complex sequence of events involved in the development of toxicity [6]. Inhibition of ODC may play an important role in this process by interfering with critical control mechanisms in the physiology of the target cells since the polyamines serve as important effectors in cellular growth, maintenance, and repair processes [7]. Points in favor of a role of this action in the expression of toxicity are the facts that neomycin has also been shown to inhibit cochlear ODC [14] and that the inhibitor constants for the aminoglycosides are in the low millimolar range for the renal enzyme. Such concentrations can be achieved in vivo in the kidney, particularly the cortex, following systemic administration of the drugs [15-18].

On the other hand, ODC is a ubiquitous enzyme and thus is a potential target of these drugs in other tissues as well. It has been suggested previously that the selective toxicity of the aminoglycosides is a result of several discrete biochemical interactions [6]. These include an active uptake process in competition with the polyamines, and disturbance of cell function through inhibition of polyphosphoinositide metabolism. In addition, specificity may also partially be attributed to the fact that renal aminoglycoside concentrations are several orders of magnitude higher than those found in other tissues [19]. This means that ODC is only inhibited by aminoglycosides if high enough intracellular drug concentrations are reached. The observation that the respective inhibitor constants of the aminoglycosides for ODC do not correlate directly with the rank order of nephrotoxicity (or for that matter ototoxicity) of these drugs [18] is in good agreement with the notion that inhibition of ODC may represent a major component of a complex injury cascade [6] rather than a single determining step. Inhibition of ODC, 
however, may constitute a crucial mechanism for the lethal effects of these drugs on susceptible cells.

Induction of ODC has been shown to be an essential component in compensatory cellular responses to injury. Enzyme activity and intracellular polyamine levels increase following cellular damage by a variety of noxious stimuli including toxic drugs $[7,8,20]$, apparently in order to adapt protein synthesis to repair processes. Inhibition of ODC by the aminoglycosides would then provide a potential mechanism by which cellular recovery is blocked. Such a block may well represent a final biochemical incult leading to death of susceptible cells.

The question then arises as to the mechanism by which aminoglycosides inhibit ODC. Although our experiments did not directly address this problem, the uncompetitive inhibition suggests a potential site of action. Uncompetitive inhibition is an attack at the enzyme-substrate complex, in this case ODCPLP-ornithine. PLP has been shown to react in vitro with the polyamine spermine and the aminoglycoside gentamicin $[21,22]$ which appears to form a Schiff base and ring structure [23] with this coenzyme. The lethal effects of these drugs in the rat in vivo can also be antagonized by PLP [23]. Since ODC has an absolute requirement for PLP [24], such an aminoglycoside action would be an example of modulation of catalytic activity through coenzyme inhibition [11].

Our results thus suggest ODC as a target of aminoglycosides in susceptible cells. Inhibition of cellular repair mechanisms mediated by ODC may be an essential component in the complex mechanisms of aminoglycoside-induced nephrotoxicity and ototoxicity.

Acknowledgement-This work was supported by research grant NS-13792 and training grant NS-07196 from the National Institutes of Health.

\section{REFERENCES}

1. W. Kusser, K. Zimmer and F. Fiedler, Eur. J. Biochem. 151, 601 (1985).
2. M. L. Kornguth. W. H. Bayer and C. M. Kunin. J. Antimicrob. Chemother. 6, 121 (1980).

3. C. Josepovitz, E. Munoz, D. Timmerman, M. Scott, S. Feldman and G. Kaloyanides, I. Pharmac exp. Ther. 223, 314 (1982).

4. S. Williams, D. E. Smith and J. Schacht, Biochem. Pharmac. 36, 89 (1987).

5. H. D. Humes, N. D. Weiner and J. Schacht, in Nephrotoxicity and Ototoxicity of Drugs (Ed. J-P. Fillastre), p. 333. INSERM, Paris (1982).

6. J. Schacht, Hear. Res. 22, 297 (1986).

7. D. H. Russell, Drug Metab. Rev. 16, 1 (1985).

8. D. H. Russell and S. H. Snyder, Proc. natn. Acad. Sci. U.S.A. 60, 1420 (1968).

9. H. U. Bergmeyer, in Principles of Enzymatic Analysis (Ed. H. U. Bergmeyer), p. 29. Verlag Chemie, Weinheim (1978).

10. J. E. Seely, H. Pösö and A. E. Pegg, Biochemistry 21, 3394 (1982).

11. J. L. A. Mitchell and D. D. Carter, Biochim. biophys. Acta 483, 425 (1977).

12. J. L. Clark and J. L. Fuller, Eur. J. Biochem. 67, 303 (1976).

13. W. A. Harris and M. J. North, J. Bact. 150, 716 (1982).

14. C. M. Henley, H-J. Gerhardt and J. Schacht, Brain Res. Bull., in press.

15. I. E. Hawkins, Jr., G. E. Boxer and C. V. Jelinek, Proc. Soc. exp. Biol. Med. 75,759 (1950).

16. M. Tachibana, O. Mizukoshi and K. Kuriyama, Biochcm. Pharmac, 25, 2297 (1976).

17. A. Schibeci and J. Schacht, Biochem. Pharmac. 26, 1769 (1977).

18. R. A. Parker, W. M. Bennett and G. A. Porter, in The Aminoglycosides (Eds. A. Whelton and H. C. Neu), p. 235. Marcel Dekker, New York (1982).

19. C. S. Desrochers and J. Schacht, Acta otolar. 93, 233 (1982).

20. G. A. Dienel and N. F. Cruz, J. Neurochem. 42, 1053 (1984).

21. R. Aigner-Held, R. A. Campbell and G. D. Davies, Jr., Proc. natn. Acad. Sci. U.S.A. 76, 6652 (1979).

22. R. C. Kenniston, Physiol. Chem. Physics 11, 465 (1979)

23. R. C. Kenniston, S. Cabellon, Jr. and K. S. Yarbrough, Toxic. appl. Pharmac. 88, 433 (1987).

24. A. E. Pegg and H. G. Williams-Ashman, Biochem.J. 109, 32 (1968). 